\author{
Marek Kuźniak \\ Uniwersytet Wrocławski, Wrocław \\ kuzniak@uni.wroc.pl \\ Elżbieta Mańczak-Wohlfeld \\ Uniwersytet Jagielloński, Kraków \\ manczak@uj.edu.pl
}

\title{
ANGIELSKIE WYRAZY OKOLICZNOŚCIOWE W POLSZCZYŹNIE
}

Słowa klucze: wyrazy okolicznościowe / meteory, przełączanie kodów, anglicyzmy, adaptacja zapożyczeń Keywords: nonce borrowings / meteors, code-switching, anglicisms, assimilation of loans

\section{Uwagi wstępne}

Jest rzeczą oczywistą, że w obecnej dobie wpływ angielszczyzny na polszczyznę jest widoczny na wszystkich poziomach języka. Na ten temat ukazało się sporo prac, niemniej, o ile nam wiadomo, dotychczas nikt nie zwrócił uwagi na tytułowe angielskie wyrazy okolicznościowe, czyli słowa utworzone ad hoc, znane w angielskiej literaturze przedmiotu jako lexical inventions (Dewaele 1998), nonce loans / ad hoc loans (Onysko 2007), nonce borrowings (Chłopek 2011) czy też meteors (Kuźniak 2009). Ta ostatnia „astrofizykalna” koncepcja ujęcia wyrazów okolicznościowych, wyprowadzona z analizy ponad 3500 wyrazów obco brzmiących w języku angielskim, jest o tyle znacząca z punktu widzenia niniejszego artykułu, że dokonuje swoistej reanalizy pojęcia borrowing/loan jako terminu odnoszącego się do wyrazów obcych zasymilowanych w języku docelowym w odróżnieniu od wyrazów obcych niezasymilowanych w tymże języku. Meteors zatem to wyrazy, których stopień zaświadczenia w korpusie, a tym samym asymilacji w języku docelowym, jest na tyle słaby, że trudno w takim przypadku mówić o kategorii zapożyczenia. 
Widać to wyraźnie w książce Marka Kuźniaka (ibid.: 136), w której wyrazy obcego pochodzenia (non-native lexis) stanowią kategorię nadrzędną wobec pozostałych kategorii poziomu podstawowego, czyli borrowings (zasymilowanych wyrazów obcych) oraz foreign words and phrases (nie w pełni zaadaptowanych obcych wyrazów i fraz) czy "unknown" words and phrases (czyli niezaadaptowanych "nieznanych” wyrazów obcych i fraz, lub może raczej „incydentalizmów”). Przywołana kategoria „meteoru” odpowiadałaby po części tytułowym wyrazom okolicznościowym (foreign words and phrases), ale również obejmowałaby „,incydentalizmy” („unknown” foreign words and phrases). Zresztą rozgraniczenie kategorii wyrazów okolicznościowo występujących w języku docelowym od wyrazów zaświadczonych incydentalnie ostatecznie jest uznaniowe, nawet jeśli wprowadzilibyśmy obiektywizujące kryteria, takie jak wskaźniki częstotliwości występowania w korpusie (zob. kategoria operacyjna CRAC (ibid.: 156-161)).

Konkludując tę część naszych rozważań, definiujemy za Pützem wyrazy okolicznościowe jako: „an incorporation from another language uttered by a single speaker in some reasonably representative corpus" (za: Onysko 2007: 37-38). Innymi słowy, wyrazy okolicznościowe tym się różnią od zapożyczeń, że są używane sporadycznie, a zarazem spontanicznie. Ponadto, jak wspomniano wyżej, charakteryzuje je niska frekwencja i stosunkowo słaba akceptacja przez innych użytkowników języka, do którego są wprowadzane (ibid.: 37). W dalszej części niniejszego artykułu zajmiemy się analizą najświeższych przykładów angielskich okazjonalizmów w polszczyźnie, opierając się na materiale leksykalnym zebranym podczas realizacji projektu zainicjowanego na stronie internetowej Instytutu Filologii Angielskiej Uniwersytetu Wrocławskiego (dalej: IFA UWr). Wcześniej jednak przyjrzymy się pokrótce socjolingwistycznym czynnikom występowania tego typu wyrażeń w procesie komunikacji.

\section{Okazjonalizmy a dwujęzyczność}

Używanie okazjonalizmów w postaci jednostek leksykalnych lub nierzadko fraz jest wynikiem przełączania kodów, co jest kolejną cechą odróżniającą je od zapożyczeń właściwych. W naszym wypadku mamy do czynienia z dwoma językami: polskim i angielskim. Naturalnie do tego przełączania dochodzi wówczas, kiedy mówcę cechuje pewien stopień dwujęzyczności. Motywacje do przełączania kodów mogą zaś mieć źródło psychosocjologiczne (identyfikacja w grupie lub chęć wyróżnienia siebie na tle grupy) lub psychobiologiczne (ekonomizacja wysiłku związanego z użyciem języka, związana na przykład ze zmęczeniem). W tym miejscu warto się zastanowić nad interpretacją pojęcia bilingwizmu, gdyż poglądy lingwistów na ten temat nie są jednolite.

Na przykład Uriel Weinreich (1979: 1) podaje bardzo ogólną definicję, sprowadzającą się do stwierdzenia, że jest to praktyka używania na przemian przez jedną osobę 
dwóch języków. Użytkownika tych języków nazywa się osobą dwujęzyczną. Należy dodać, że Weinreich uważa, iż istnieją rozmaite stopnie dwujęzyczności, począwszy od swobodnego posługiwania się dwoma językami, a skończywszy na znikomej znajomości drugiego języka, który nie jest rodzimym. Z kolei Einar Haugen (1953) twierdzi, że o bilingwizmie można mówić dopiero wówczas, gdy mówiący jest w stanie konstruować w drugim języku wypowiedzi całkowite i sensowne. Zarówno jednak kategorię znikomej znajomości języka, jak i pełności oraz sensowności wypowiedzi trudno rozpatrywać z punktu widzenia zobiektywizowanego osądu i ostatecznie obie skazane są na kryterium introspekcyjne.

Leon Zawadowski (1985) z kolei zwraca uwagę na to, że język jest zjawiskiem społecznym i z tego powodu nie można definiować pojęcia bilingwizmu w odniesieniu do jednego mówcy, jak to czynią wyżej wymienieni językoznawcy amerykańscy. Poza tym twierdzi, że jest konieczne rozróżnienie częstego użycia dwu języków dla różnych celów i okazjonalnego posługiwania się dwoma językami, jak w wypadku nauki języka obcego lub okazjonalnej rozmowy z cudzoziemcem. Według Zawadowskiego jedynie pierwsza sytuacja jest związana $\mathrm{z}$ kontaktem językowym, który prowadzi do bilingwizmu. Podobną socjologiczną lub raczej etnocentryczną interpretację terminu dwujęzycznośćl bilingwizm znajdujemy w EJO:

Posługiwanie się przez daną grupę społeczną dwoma różnymi językami. Dwujęzyczność wytwarza się na terenach o mieszanym składzie etnicznym. Konieczność współżycia na co dzień zmusza przedstawicieli jednej narodowości do używania oprócz swojego języka ojczystego również języka drugiej grupy etnicznej. Dwujęzyczność występuje np. na niektórych obszarach Szwajcarii (najczęściej niem.-franc.), Belgii (flam.-franc.) [...]. Najczęściej bilingwalni są przedstawiciele grupy etnicznej, która z przyczyn społeczno-gospodarczych czy politycznych odgrywa mniejszą rolę w danym kraju, np. Łużyczanie w Niemczech [...] (EJO: 130).

Druga z opisywanych przez Zawadowskiego sytuacji, czyli okazjonalne użycie języka drugiego $\mathrm{w}$ rozmowie $\mathrm{z}$ cudzoziemcem, nie prowadzi rzecz jasna wprost do bilingwizmu rozumianego jako kategoria socjolingwistyczna, lecz, jak sądzimy, może stanowić element pośrednio wspierający dwujęzyczność rozumianą tutaj raczej jako kategoria dyskursywna.

W niniejszym artykule przyjmujemy zatem za Weinreichem (1979), że pojęcie $d w u$ języczność ma charakter bardziej ogólny i odnosi się do różnych poziomów znajomości języka drugiego. Do tego dochodzi aktualizacja owej znajomości w różnych kontekstach sytuacyjnych, co czyni dwujęzyczność kategorią dyskursywną. Wychodzimy bowiem z założenia, że osoby znające angielszczyznę (w naszym wypadku) nawet w znikomym stopniu są w stanie używać angielskich wyrazów okolicznościowych w języku polskim, kierując się różnorodnymi motywacjami, najczęściej o podłożu psychospołecznym (zob. m.in. Mańczak-Wohlfeld 1995: 15-16). 
Jak pisze Zofia Chłopek (2011: 144-145), wprowadzanie tzw. nonce borrowings nie świadczy o brakach w kompetencji językowej, lecz stanowi świadomy i w jakimś sensie naturalny sposób komunikowania się - w naszych rozważaniach - Polaków znających w pewnym stopniu język angielski. Choć, jak uważa Jean-Marc Dewaele (1998: 84), przełączanie kodów i w prowadzanie pożyczek okazjonalnych jest swoistego rodzaju „leniwą" możliwością zachodzącą w komunikacji. Warto jednak dodać, że jakkolwiek pożyczki ad hoc są konsekwencją procesów zachodzących "na potrzeby chwili”, to mogą stać się częścią idiolektu jednego mówcy lub jego otoczenia, a także po pewnym czasie wejść na stałe do polszczyzny, i tym samym zostać uznane za leksykalne, semantyczne bądź frazowe zapożyczenia angielskie. Czynnikiem decydującym o przejściu procesu adaptacji danego okazjonalizmu jest jego frekwencja w danym języku drugim, mierzona jako stosunek liczby wystąpień danego lematu w korpusie do liczby tekstów, w których hasło to jest zaświadczane. Jeśli dany termin obcojęzyczny występuje dziesięć razy w pięciu tekstach w korpusie języka docelowego, to wówczas jego wartość operacyjna jest obliczona jako średnia arytmetyczna liczb 5 oraz 10, czyli wynosi $7,5^{1}$. Tak obliczony wynik stanowi w przyjętym przez Kuźniaka (2009) modelu „masę” takiego obcego lematu, a ta z kolei jest skorelowana z potencjałem asymilacyjnym w języku docelowym. Uważa się, że anglicyzmy okazjonalne występują przede wszystkim w języku nieformalnym, zarówno mówionym, jak i pisanym (głównie dotyczy to wszelkich form komunikacji elektronicznej). Według Chłopek:

Sposób i intensywność stosowania pożyczek ad hoc i przełączeń kodów zależą od szeregu czynników społecznych, politycznych, historycznych i demograficznych, właściwych danej społeczności dwu-/wielojęzycznej. Także rozmaite motywy indywidualne wpływają na mieszanie języków przez osoby dwu-/wielojęzyczne. Na przykład elementy języka niebazowego mogą zostać wykorzystane dlatego, że (1) w trafniejszy lub ekonomiczniejszy sposób wyrażają dane pojęcie, (2) są dostępniejsze dla osoby mówiącej (tzw. most available word phenomenon) [...], (3) umożliwiają uwypuklenie pewnych istotnych elementów wypowiedzi albo (4) ułatwiają wyrażenie emocji [...]. Oprócz tego, istnieją określone czynniki natury językowej, które kształtują i ograniczają sposoby mieszania języków przez osoby co najmniej dwujęzyczne (Chłopek 2011: 145).

Autorka zwraca uwagę na to, że wprowadzanie pożyczek będących przedmiotem niniejszej analizy może stanowić wynik zarówno zautomatyzowanego, a więc nieświadomego, jak i celowego, czyli świadomego mieszania języków. Tutaj jednak napotykamy problem nieweryfikowalności świadomego czy też nieświadomego użycia języka jako kategorii intencjonalnych.

1 Więcej na temat wspomnianej wyżej kategorii CRAC oraz jej podstaw empirycznych zob. Kuźniak 2009. 


\section{Empiryczne podstawy wyłaniania okazjonalizmów}

Nie wgłębiając się w nierozwiązywalne zagadnienia terminologiczne czy też metodologiczne, opowiadamy się za maksymalnie empirycznym, „oddolnym” ujęciem badania okazjonalizmów. W rezultacie przedmiotem naszej analizy stał się korpus ponad 800 okolicznościowych pożyczek leksykalnych, semantycznych i frazowych pochodzenia angielskiego, zarejestrowanych w latach 2010-2012 w IFA UWr. Korpus ten został stworzony przez studentów anglistyki, poproszonych, by na specjalnie utworzonej stronie internetowej wpisywali słowa lub frazy, nazwane meteorami / drażliwymi zapożyczeniami, których sami okazjonalnie używają lub które choćby incydentalnie spotkali w polskich tekstach mówionych bądź pisanych. Należy wyjaśnić, że z oczywistych względów niektóre hasła się powtarzały (tzn. zostały zarejestrowane w systemie dwa-trzy razy), stąd liczba przebadanych jednostek de facto była nieco mniejsza.

\section{Analiza okazjonalizmów angielskich w polszczyźnie}

Następny problem związany z analizą danych korpusowych dotyczył poziomu integracji okazjonalizmów z językiem polskim, który okazał się bardzo różny. Część wyrazów zebranych w bazie odpowiada zatem kategorii zapożyczenia, część jest zwykłymi wyrazami okolicznościowymi. Cechą charakterystyczną tych ostatnich jest niestabilność w pejzażu leksykalnym polszczyzny, przez co ich szanse na trwałą asymilację w języku docelowym należy uznać za iluzoryczne. W modelu eksplikacyjnym Kuźniaka (2009) wyrażenia tego typu porównuje się do meteorów na nieboskłonie, znikających niedługo po pojawieniu się w polu widzenia obserwatora i pozostawiających nietrwały ślad $\mathrm{w}$ jego umyśle. Zgodnie z uwagami przedstawionymi wyżej stopień asymilacji lub jego brak stały się podstawą sklasyfikowania zebranego materiału (zob. Haugen 1953). Mamy zatem:

I. CYTATY (niepodlegające adaptacji w języku polskim):

a) Jednowyrazowe, np.:

actually; adorable; afterparty; and; anyway; apple; appropriate; baby; beautiful; bed; big; binary; bird; bitch; blowjob; break; bumper; busy; butterfly; carlicious; circumstance; click; computer; confide; confused; contestant; crasher; crusher; cute; damn; dance; dancefloor; dictionary; diet; doubts; drama; earth; edge; English; entertainment; epic; evanescence; ever; fashion; fire; flag; floor; framework; free; friendship; go; grill-man; hard; hero; holiday; horny; idiom; idiomatic; leadership; level; life plan; litter; look; lovely; man; manual; match-fixing; matter; me; mock; money; moron; mother; nice; outfit; patch; pick up; pigeon-hole; please; 
polluted; poo; Pope; progress; prose; quest; refill; research; rulet; sand; scrapbooking; screen; shooter; shopping; show story; something; stuff; success; swag; sympathetic; thanks; ultimate; want; whatever; whisper; workflow; you.

b) Będące frazami lub nawet zdaniami, np.:

active freeze; attention whore; batty boy; big love; by the way; can you see it?; coffee'sgo; drink positive; energy drink; extra large; face palm; good bye appetite; greatest hits; green tea; horror show; how are you?; in your face; kind of; kissing point; let's color; low-key campaign; lucky loser; must be the music; must have; no way; oh yeah; pace of life; plain text; relax! shut your face; sneaky bitch; sneaky fucker; strong Man; summer sale; Take it easy!; tell me about it; that's what she said; the voice of Poland; toy shop; truck division; upper intermediate; urban card; wedding planner; what the fuck?!; who knows?; XXL size.

Jak widać, obie grupy cechuje zachowanie angielskiej pisowni. Trudno na podstawie grafii stwierdzić, w jaki sposób wyrazy te są wymawiane, ale z pewnością, jeśli uwzględnić różnice między angielskim i polskim systemem fonologicznym, nie są one wiernym fonetycznym odzwierciedleniem angielskich pierwowzorów, jakkolwiek można domniemywać, iż polscy angliści, podobnie jak osoby dwujęzyczne, starają się je wymawiać w sposób możliwie najbardziej zbliżony do oryginału. Na poziomie morfologicznym dochodzi do Haugenowskiego (Haugen 1950) przeniesienia. Podobnie jest na płaszczyźnie semantycznej, jakkolwiek warto zwrócić uwagę na to, że omawiane okazjonalizmy przejmują z angielszczyzny tylko jedno znaczenie. Na przykład CALD (2008) podaje cztery znaczenia leksemu earth, podczas gdy w polszczyźnie pojawił się on tylko w jednym $\mathrm{z}$ nich - 'ziemia'. Ponadto $w$ języku angielskim w niektórych wypadkach dochodzi do tzw. konwersji (conversion), czyli użycia tej samej formy wyrazu jako dwóch różnych części mowy, np. research: jako rzeczownika i czasownika, natomiast wydaje się, że ta jednostka leksykalna bywa używana w polszczyźnie wyłącznie jako rzeczownik, a więc do analogicznego zwężenia dochodzi również na poziomie morfologicznym.

\section{ASYMILACJA NA POZIOMIE GRAFICZNYM:}

Jak wynika z nazwy tej grupy, tworzą ją wyrazy zapisane według polskiej ortografii. Można przypuszczać, że są one wymawiane zgodnie z ich zapisem graficznym, co jest cechą charakterystyczną dla języka polskiego, np: [eim], [inwojs], [kul], [łisky], [risercz], [tjuning], [luk], [engzajeti], [cleimsy] (ciekawy przykład użycia podwójnej liczby mnogiej i niekompletnej adaptacji na poziomie grafii, gdyż zachowano ang. $c$ zamiast polskiego $k$ ), [cziter], [lucy] (jest to imię własne, więc wyraz ten powinien być zapisany przez $L$, jak w innym przykładzie - Dżizus). W tym miejscu nasuwa się refleksja, czy nomina propria powinny być traktowane jako zapożyczenia. Wiadomo, 
że lingwiści nie są w tym zakresie zgodni (zob. dyskusję w: Kuźniak 2009: 142-151). Większość z nich jednak nie uznaje ich za pożyczki właściwe. Najwyraźniej respondenci w przeprowadzonym badaniu uważali, że są to elementy przejęte $z$ angielskiego. W tym wypadku można się zgodzić $\mathrm{z}$ taką interpretacją, gdyż w języku polskim znajdujemy odpowiedniki niektórych z wymienionych nazw własnych (np. Jezus). Pełna ${ }^{2}$ lista okazjonalizmów zaadaptowanych graficznie wygląda następująco:

bauns; cozy; czik; cziter; duszbag; dżi dżi; dżizas; Dżizus; enerdżajzer; engzajeti; fakap; fanpejdz; fejk; fejs; hejter; inwojs; kaman; kejs; kłesczjon; kołcz (trener); kołczing; kompetycja; kontent; krap; kul; lucy; luk; łiski (zamiast szkocka); lumenajzer; masakrejszyn; mikstejp; najs; no łej; nołlajf; obdżektor; ofsajd; performens; plejmejker; plis; poker fejs; prowajder; respekt; risercz; saport; senk ju; si ja; siet/ szit; stit; spicz; szoping; szot; tap madl; tejk ker!; tim; tjuning.

\section{ASYMILACJA NA POZIOMIE MORFOLOGICZNYM:}

a) Dodanie polskich morfemów typowych dla czasowników (-ować, -ać, -nać) , np.: apdejtować; apgrejdować; czejsować; debunkować; dissować; dizgastować; fakować; filowaćlfajlować; hejpować; hejtować; hugnać; interruptować; kancelować; keszować; kolnąć/callnać; komitować; linkować; looknaćlluknać; lovciać; obrendować; otamować; ownować; passować; pullować; puszować; requestować; resemblować; riskitować; rozzipować; saportować; sczekałtować; shipować; skilować; submitować; szitować,

albo polskiego znacznika mianownika liczby mnogiej (-y), np. eventy, gifty, lub wreszcie sufiksów przymiotnikowych (-owy, -alny, -cki, -ny, -aśny), np.:

akcydentalny; casualowy; czipacki/cheapacki; dyrektny; efuzywny; impozywny; kazualny; każualowy; lajfstajlowy; outdoorowy; randomalny; stitaśny; sweetaśny/ switaśny; wysofistykowany; zdissowany; zsanowany.

b) Użycie polskich aspektualnych prefiksów derywacyjnych $(z-/ s-)$ z czasownikami: zafajlować, zakomitować, zawrapować, zczekałtować, zfriendzonować, zmerdżować, zreszarować, zupgrejdować.

Jest rzeczą ciekawą, że część z wyżej wymienionych przykładów już weszła na stałe do potocznej polszczyzny, jednak znakomita większość pozostaje na jej peryferiach, co znajduje potwierdzenie w ich śladowej obecności w Narodowym Korpusie Języka Polskiego.

2 Oczywiście w rozumieniu korpusu zebranego z witryny internetowej IFA UWr w latach 2010-2012. 


\section{FORMACJE HYBRYDOWE:}

Jak wskazuje nazwa, są to połączenia wyrazów polskich i angielskich, np. pozyskiwać sampla, must have sezonu, będziemy w taczu, być happy, dać komuś lajka, formuła micro protect, idę na break'a, 15-itemowy test, fokusować uwage, spódnica w printy, wystać komuś tekst (pochodzące od ang. to text, czyli 'wysłać esemesa'; polski element został tu więc zachowany, a dodano ang. text (pol. tekst), co między innymi oznacza po angielsku esemesowanie). Jak zatem widać, niektóre frazy angielskie są przejmowane i włączane do polszczyzny w sposób niepozwalający się jednoznacznie skategoryzować.

Zanalizujmy jeszcze wyrażenia komituje suisajda, strong womanka, mieć dobry czas. $\mathrm{W}$ zasadzie każde z tych sformułowań jest ilustracją innego typu spolszczenia. Pierwszy przykład pochodzi od ang. commit suicide, a więc mamy tu do czynienia $\mathrm{z}$ adaptacją graficzną, fonetyczną, morfologiczną oraz przeniesieniem na poziomie semantycznym. Drugi to ang. strong woman, w którym do wyrazu woman dodano sufiks - $k a$ na oznaczenie rodzaju żeńskiego. Z kolei trzecia fraza stanowi ilustrację semantycznej pożyczki od ang. have a good time. W tym miejscu warto dodać, że także nieliczne pojedyncze wyrazy są pożyczkami semantycznymi, np. papier z ang. paper 'referat'.

Podsumowując, formacje hybrydowe są niejako z natury rzeczy wielopoziomowymi adaptacjami, co znaczy, że można wyszczególnić kontaminacje poziomu fonetycznego, graficznego, morfologicznego, a w przypadku omawianych wyżej formacji hybrydowych złożonych również na poziomie składni. Poniżej zamieszczamy pełną listę konstrukcji hybrydowych z podziałem na proste (wewnątrzwyrazowe) oraz złożone (właściwe), będące konstrukcjami wielowyrazowymi.

Wielopoziomowe (leksykalne):

assesmenty kierownicze; bajk piknik; biforek; blogasek; clejmsy; ello; fashionistkal faszynistka; fejsik; frendsy; fulle (o grach komp.); gifty/gratisy; ingredienty; inteligibilność; karesy; kisski; krezol; kudbiś; kustomizacja; lokalsi; madafaka; makeupistka; makingoffy; milfetka; okejka; oki; plagiaryzm; qwerty; redempcje; refutacja; socjal network; stile; strong womenka; surpriza; sweetfocia; szopaholik.

Wielopoziomowe (składniowe):

15-itemowy test; ale o co kaman?; aplikować na rolę; bez endu; będziemy w taczu; brać holidaya; być (całym) happy; być creepy; być w touchu; cały/a happy; cel-shadingowa gra; cierpieć na prokrastynację; dać komuś lajka / lajknaćc; dać lajka na fejsiku; dowód dla tego kleimu; ejm; element saspensu; fan speedwaya; formuła micro protect; idę na break'a; idziemy na bauns; immoralny czyn; jestem busy; jestem jego replacement; jesteśmy w intaczu; komitną́ suisajda (ang. commit suicide); kultowy slasher; kupować menshelta; launch brandu; lunch pakiet; mam skilla (odn. posiadania jakiejś umiejętności); mieć fun; mieć z sobą guna; must have sezonu; nasi remowi; naturalny look; nie approvuje go; o co kaman?; 
on jest fishy; poczuć feeling; podziemny underground; postnuklearny shooter; pozyskiwać sampla; przyjęcie Tea \& Cake; re otwarcie; robić research; rozmowy bez endu; różne sorty ciekawostek; sfokusować na targecie; sklep multibrandowy; spódnica w printy; to nie jest fer; totalny must; ty lajerze; wishlista; wystać komuś text; zawsze overreactingujesz i overthinkujesz; zrobić printscreena I zrobić screena.

Analizując zebrany materiał, należy też zwrócić uwagę na dwojakiego rodzaju pomyłki. Otóż respondenci błędnie zakwalifikowali niektóre wyrazy jako zapożyczenia angielskie, podczas gdy ich pochodzenie jest odmienne, np. metheor (powinno być meteor) pochodzi z greki, frekwencja i redundancja - z łaciny, a vodka - z rosyjskiego (zob. SWO). Można w tym przypadku mówić o quasi-anglicyzmach w sensie synchronicznym, uwzględniającym nieekspercki poziom świadomości językowej użytkowników polszczyzny, oraz o pseudoanglicyzmach w sensie historycznym, tj. etymologicznym, a zatem uwzględniającym tzw. wiedzę ekspercką. Odnotowane w tej kategorii wyrażenia obejmują również poniższe:

agenda; ambarasujący; animator; atencja; destylacja; dyskrepancja; dyspersja; dystynkcja; egzageracja; ekstraordynaryjny; emfaza; ewaluacja; ewaluować; finalnie; fleksybilny; frekwencja; imposybilizm; indyferentny; inhibitor; inkorporować; kiwi; koincydencja; kopia; medium; menu; meteor; moment; obligatoryjny; paragraf; partycypować; partykularny; permanentnie; prefiguracja; probabilistyczny; profetyczny; progres; prohibicja; promiskuidalny; redundancja; spauzować; spetryfikowany; subregion; subskrybować; subskrypcja.

Ponadto niektóre z wpisanych wyrazów, jak zaznaczono wyżej, to anglicyzmy od dłuższego już czasu funkcjonujące w polszczyźnie, np.: break, clubbing, chippendales, deadline, design, developer (możliwa jest też pisownia przez w), helicopter (jest to zapożyczenie, którego pisownia została już spolszczona: helikopter) czy hardcore (który cechuje tendencja odwrotna, czyli spolszczenie pisowni przez niektórych studentów: hardkor). Kompletny zestaw „świeżych” anglicyzmów zasymilowanych lub też nie w pełni zasymilowanych w polszczyźnie przedstawia się następująco:

bekon; bicykle; blogerka; bookować; bowling; boysband; break; briefing; bye; chippendales; clubbing; coaching; cool; czilloucik; czirliderka; deadline; design/ dizajn; developer; dog; dogoterapia; dressingi (do sałatek); enter; establishment; evenciarz; event(y); exit pools [czyt. puls]; fajter; feedback; fighter; football; forwardować/sforwardować; Freestyle; fristajlowy; futbolista; gayparty; gentleman's agreement; glamour; golkiper; handout; hardcore; helicopter; helo; hipster; house; human resources; ice tea; image/imidz; jazzy; kidnaper; know-how; korner; kros; kurs e-learningowy; laikować na facebooku; lajk; lajkować; lancz; last but 
not least; layout; lightowy; live w 3D; love; lunch; mainstream; mainstreamowy; menager; mityng; mixować; lobbing; monitoring; multiroom; nick; ok; old schoolowy; outlet; outsourcing; party; pay per view; pecet; pendrive; playmaker; postować; power; pressing; public relations; randomowy; real; remake; sale; sandwich; sexy; sfokusować; sforwardować; shit; shopping; snajper; soccer; sorki; sorewicz; sorry/sory; soundtraki; speedway; spojlerować; sponsoring; squatter; stalking; stand-up; star; strong; superstar; superwizor; surwiwal; sylabus; szit; take away; target; top model; topowy; topy; trendsetter; trendy; tuning; tuningować; tutorki; tweetnać; voucher; weekend; widżety; wow!; wylajtowany/wylajtować się; yep; yes; zabukować; zalajkować; zaserwować.

Osobną kategorią okazjonalizmów, choć stosunkowo rzadko notowaną we wspomnianym korpusie, są kalki strukturalne oraz neosemantyzmy. Można tutaj wyróżnić następujące konstrukcje: dokładnie; mieć dobry czas; wspomniany papier (referat); weź swój czas; zrobić różnicę. Inną słabo zaświadczoną kategorią są akronimy, których zarejestrowano w ponadosiemsetwyrazowym korpusie zaledwie kilka: $B T W ; C U$; LGBT; LOL; NGOs; OMG; WTF.

\section{Podsumowanie}

Można przyjąć założenie, że przeciętnie wykształcony użytkownik języka polskiego używa angielskich okazjonalizmów rzadziej. Naturalnie ta uwaga nie odnosi się do pracowników międzynarodowych korporacji, w których, jak wiadomo, angielskie wyrazy i zwroty są wręcz nadużywane. Podobnie rzecz się przedstawia w pewnych środowiskach związanych z anglo-amerykańską kulturą, np. w przypadku osób zainteresowanych muzyką współczesną.

Kończąc, warto zwrócić uwagę na kontrowersje pojawiające się w literaturze przedmiotu, dotyczące traktowania wyrazów okazjonalnych. Niektórzy lingwiści uważają, że należy je uznać za zapożyczenia właściwe (np. wspomniany Onysko 2007). Naszym zdaniem, stanowią one odrębną kategorię językową, różną od zapożyczeń właściwych pod względem stopnia asymilacji w języku docelowym, co zostało zdefiniowane w pierwszej części artykułu, a czego potwierdzeniem jest zebrany i przeanalizowany materiał.

\section{Literatura}

CALD: Cambridge Advanced Learner's Dictionary, Cambridge 2008.

Снџорек Z., 2011, Nabywanie języków trzecich i kolejnych oraz wielojęzyczność. Aspekty psycholingwistyczne (i inne), Wrocław.

DeWAele J.-M., 1998, Lexical inventions: French interlanguage as L2 versus L3, „Applied Linguistics" t. 19/4, s. 471-490. 
EJO: K. Polański (red.), Encyklopedia językoznawstwa ogólnego, Wrocław-Warszawa-Kraków 1999.

Haugen E., 1950, The analysis of linguistic borrowing, „Language” t. 26/2, s. 210-231.

Haugen E., 1953, The Norwegian Language in America. A Study in Bilingual Behavior, Philadelphia, Pennsylvania.

Kuźniak M., 2009, Foreign Words and Phrases in English. Metaphoric Astrophysical Concepts in Lexicological Study, Wrocław.

MAŃCZAK-WoHlfeld E., 1995, Tendencje rozwojowe współczesnych zapożyczeń angielskich w języku polskim, Kraków.

Onysko A., 2007, Anglicisms in German. Borrowing, Lexical Productivity, and Written Codeswitching, Berlin-New York.

SWO: E. Sobol (red.), Słownik wyrazów obcych. Wydanie nowe, Warszawa 1999.

Weinreich U., ${ }^{9} 1979$, Languages in Contact. Findings and Problems, Berlin.

ZAwAdowski L., 1985, A recent synthesis of language contact, „Biuletyn Polskiego Towarzystwa Językoznawczego" XXXIX, s. 175-191.

\section{English nonce borrowings in Polish \\ Summary}

The article discusses the latest English nonce borrowings in Polish. The study, which is based on the project initiated by the Department of English Studies at Wrocław University, embraces ca. 800 units of varied complexity. The argument that arises from the analysis is that the category of nonce borrowings or "meteors" should be carefully distinguished from other related categories, if we take the criterion of the degree of assimilation in the target language as the key factor. In consequence, the superordinate category is formed by the all-inclusive notion of non-native lexis which further includes as its subcategories borrowings proper (well-assimilated units), foreign words and phrases (semi-assimilated units), and "unknown" foreign words and phrases (non-assimilated units). The category of nonce borrowings is postulated to reside in the area covering the scope of foreign semi- and non-assimilated units in the target language. 